\title{
Ameliorative Efficacy of Egyptian Pyramid Model Housing on Unilateral Nephrectomized Rats
}

\author{
Sohair R Fahmy*, Khadiga Gaafar, Dawlat A Sayed and Huda Nageeb \\ Department of Zoology, Faculty of Science, Egypt
}

Received: 制: December 12, 2018; Published: ㄴㅔㅛ: January 03, 2019

*Corresponding author: Sohair R Fahmy, Department of Zoology, Faculty of Science, Egypt

\begin{abstract}
Background: Chronic Kidney Disease (CKD) is a worldwide health threat. The Pyramids of Egypt are one of the world's most amazing achievements. Thereby, the present study aims to investigate the ameliorative efficacy of housing Unilateral Nephrectomized (UNx) rats inside model of the great Egyptian pyramid.

Results: Housing UNx rats for 24 and $48 \mathrm{~h}$ inside the Egyptian pyramid model induced significant increase in the weight of the right kidney, serum sodium and calcium levels and potassium ions excretion in urine. Creatinine clearance increased significantly after housing UNx rats inside the Egyptian pyramid model following $48 \mathrm{~h}$. However, housing of rats inside the Egyptian pyramids for 24 and $48 \mathrm{~h}$ ameliorate kidney function markers (proteinuria, urea and uric acid) and restore their levels towards the control values. In addition, levels of the reinin, angiotensin and aldosterone hormones significantly increased after housing UNx rats inside the Egyptian pyramid for 24 and $48 \mathrm{~h}$.

Conclusion: The present study showed that housing nephrectomized rats inside model of the Egyptian pyramid may be a potential new strategy prevents CKD following renal tumour resection. Also, the current study suggested that pyramid environment plays an important role in ameliorating the serious effects of nephrectomy by enhancing kidney function.
\end{abstract}

Keywords: Egyptian Pyramid Models; Unilateral Nephrectomized Rats; Kidney Functions; Renin-Angiotensin-Aldosterone System; Rats

\section{Introduction}

Nephrectomy $(\mathrm{Nx})$ is a novel intervention having first been introduced for the treatment of renal cell carcinoma in 1969 [1]. Although surgical resection remains the standard of care in the treatment of renal carcinoma, $\mathrm{Nx}$ is also a recognized risk factor for developing Chronic Kidney Disease (CKD) [2,3]. Indeed, nephrectomy is a widely used model to study the mechanisms leading to renal damage in CKD [4]. The intra-renal vasculature is the most affected structure, preventing an appropriate blood flow, favoring the glomerular sclerosis [5]. CKD will certainly lead to the progression of Chronic Renal Failure (CRF) due to gradual sclerosis of renal tissue. In addition, nephrons are gradually lost in renal failure. Remaining nephrons are hypertrophied to compensate for the loss of renal function, and hyperfiltration in these remaining nephrons leads to further nephron loss [6].

Models with the same dimensions of the great Egyptian pyramid of Giza are believed to generate, transform and transmit energy when aligned on a true north south axis [7]. The energy generated inside these models is of the electromagnetic spectrum and other forms or degrees of the so-called universal energy [8]. There is valid and important relationship between electromagnetic energy and the human body [9]. Human body flourishes in an electro-chemical environment, which is activated by its response to electromagnetic energy [10]. Razumov et al. [11] reported that electromagnetic waves induced a marked hemodynamic action in kidney via stimulation of the circulation of the intermediary zone with an effect of redistribution of the intra-renal blood flow. It was reported that the energy field developed within the pyramid may increase the Glomerular Filtration Rate (GFR) by increase in the renal blood flow following unilateral nephrectomy for 7 and 14 days [12]. The present study postulated that early preventing renal sclerosis following unilateral nephrectomy in rats may be achieved through improvement of the rheological properties of the blood under the effect of electromagnetic spectrum of the pyramid model that could delay the progression of the CRF. Thereby, the present study aims to investigate the ameliorative efficacy of housing 
Unilateral Nephrectomized (UNx) rats inside model of the great Egyptian pyramid.

\section{Materials and Methods}

\section{Experimental Animals}

Healthy male Wistar albino rats (Rattus norvegicus), weighing 180-200g, were used. The animals were obtained from the National Research Center (NRC), Egypt. The rats were kept for one week before the commencement of the experiment for acclimatization. Animals were grouped and housed in polypropylene cages (five animals per cage) in air conditioned room at temperature of 25 $\pm 1{ }^{\circ} \mathrm{C}$ and under natural day and night cycle. Animals were feed standard chow pellets and drinking water.

\section{Ethical Consideration}

The experimental protocol was approved by the Institutional Animal Care and Use Committee (IACUC) (CUFS/S/PHY/15/14) of Faculty of Science, Cairo University, Egypt.

\section{Pyramid Model Design and Dimensions}

A wooden pyramid model (Figure 1) of $30 \mathrm{in}$. height, $45 \mathrm{in}$. base and 41.5 sides was fabricated locally and used during the present [12].

Figure 1: Design of Egyptian pyramid model.

\section{Unilateral Nepherectomy}

Unilateral nepherectomy was performed according to Fahmy et al. [12]. Briefly, laparatomy was performed under antiseptic conditions after anesthetization of rats with sodium pentobarbital ( $50 \mathrm{mg} / \mathrm{kg}$ body weight; ip). The left kidney was removed following small longitudinal abdominal incision which then closed using a 4-0 silk thread (UNx group). In sham-operated animals, the left kidney was exposed and gently manipulated but left intact (sham group). All animals received normal saline of equal volume at corresponding time points. All the rats received $50 \mu \mathrm{l}$ of $0.2 \%$ ropivacaine subcutaneously for the post-operative analgesia.

\section{Experimental Design}

Fourty two male Wistar rats were assigned equally into three main groups (14 rats for each).The sham-operated control (sham group) and unilateral nephrectomized rats (UNx group). Both groups maintained in their home cages for $24 \mathrm{~h}$ and $48 \mathrm{~h}$. The third group (Pyramid housed group) in which UNx rats housed within the wooden pyramid (6hr/day) for $24 \mathrm{~h}$ and $48 \mathrm{~h}$ [13].

\section{Urine Collection and Preparation}

At the end of each experimental period, the rats were transferred to individual metabolic cages for $24 \mathrm{~h}$ and urine was collected. During this time, the rats had free access to water. The collected urine samples were freed from fecal contamination and the urine volume was measured by using the measuring cylinder.
The urine samples were centrifuged for 10 minutes and the urine supernatant was then stored at $-70{ }^{\circ} \mathrm{C}$ until analysis.

\section{Animals Handling}

Animals were euthanized under deep anaesthesia with sodium pentobarbital. Blood was collected in centrifuge tubes then centrifuged at $3000 \mathrm{rpm}$ for 20 minutes. Serum stored at -20 ${ }^{\circ} \mathrm{C}$ until used for biochemical and hormonal assays. Right kidney was removed and immediately blotted using filter paper to remove traces of blood and weighted then suspended in $10 \%$ formal saline for fixation preparatory to histological processing.

\section{Determination of Electrolytes in Urine and Serum Samples}

The appropriate kits (Bio-Diagnostic, Dokki, Giza, Egypt) were used for the determination of sodium, potassium and calcium ions by colorimetric method according to the method described by Trinder [14]; Sunderman and Sunderman [15] and Gindelar and king [16] respectively.

\section{Determination of Renal Function in Urine and Serum Samples}

Urea was determined by urease-berthelot method using Biodiagnostic kits, according to the method described by Fawcett and Soctt [17]. Total protein was determined by colorimetric method using Biodiagnostic kits, according to the method described by Gornal et al. [18]. Uric acid was determined by enzymatic 
colorimetric method using Biodiagnostic kits, according to the method described by Barham and Trinder [19]. Creatinine was determined by colorimetric method (End Point) using Biodiagnostic kits, according to the method described by Schirmeister et al. [20]. Creatinine Clearance was determined according to the following equation:

Creatinine Clearance $(\mathrm{ml} / \mathrm{min})=\frac{m g \text { creatinine / dl urine } x \mathrm{ml} \text { urine } / 24 \mathrm{hrs}}{m g \text { creatinine / } d l \text { serum } x 1440}$

\section{Hormonal Analyses}

Plasma levels of renin, angiotensin and aldosterone were determined using mouse/rat ELISA kits (Cat\# SL0617Ra, SL0061Ra and SL0040Ra, respectively, Sunlong Biotech Co. LTD).

\section{Statistical Analyses}

Statistically, the data of the present study were analysed according to Shapiro-Wilk and Kolmogorov analysis. All the statistical analyses done on the bases of the parametric analysis as the raw data were normally distributed. Values were expressed as mean \pm SEM. To evaluate differences between the groups studied, one way Analysis of Variance (ANOVA) with the simple t-test was used to compare the group means and $\mathrm{P}<0.05$ was considered statistically significant. SPSS for Windows (version 15.0) was used for the statistical analysis.

\section{Results}

\section{Effect of Egyptian Pyramid Housing on Right Kidney Weight in Unilateral Nephrectomized Rats (UNx)}

Housing UNx rats either inside their home cages or inside the Egyptian pyramid model induced significant increase $(\mathrm{P}<0.05)$ in the weight of the right kidney as compared to sham group following 24 and $48 \mathrm{~h}$ of nephrectomy, respectively (Table 1 ).

Table 1: Effect of Egyptian pyramid housing on right kidney weight (g) in Unilateral Nephrectomized Rats (UNx).

\begin{tabular}{|c|c|c|c|}
\hline \multirow{2}{*}{$\begin{array}{c}\text { Time Periods } \\
\text { (h) }\end{array}$} & \multirow{2}{*}{ Sham } & \multicolumn{2}{|c|}{ UNx } \\
\cline { 3 - 4 } & & Home Cage & Pyramid \\
\hline 24 & $0.66 \pm 0.03$ & $0.74 \pm 0.02^{\mathrm{a}}$ & $0.75 \pm 0.01^{\mathrm{a}}$ \\
\hline 48 & $0.67 \pm 0.03$ & $0.83 \pm 0.04^{\mathrm{a}}$ & $0.89 \pm 0.03^{\mathrm{a}}$ \\
\hline
\end{tabular}

Note: Values are means \pm SEM ( $n=7$ per group) a: Significant at $(\mathrm{P}<0.05)$ as compared to the corresponding sham group. $b$ : Significant at $(\mathrm{P}<0.05)$ as compared to the corresponding home cage group.

\section{Effect of Egyptian Pyramid Housing on Some Urine and Serum Electrolytes in Unilateral Nephrectomized Rats (UNx)}

Data recorded in Table 2 showed that unilateral nephrectomy induced significant $(\mathrm{P}<0.05)$ increase in the urine sodium and calcium levels concomitant with marked decrease of their serum levels as compared to the corresponding sham group. However, housing of UNx rats inside the Egyptian pyramid for 24 and $48 \mathrm{~h}$ induced significant $(\mathrm{P}<0.05)$ decrease in the urine sodium and calcium levels with increase in their serum level as compared to UNx rats that housed in their home cage. Levels of urine potassium ions decreased significantly $(\mathrm{P}<0.05)$ following nephrectomy for 24 and $48 \mathrm{~h}$ as compared to the corresponding sham groups (Table 2). Housing of nephrectomized rats inside the Egyptian pyramid for 24 and $48 \mathrm{~h}$ significantly $(\mathrm{P}<0.05)$ increased potassium ions excretion in urine.

Table 2: Effect of Egyptian pyramid housing on some urine and serum electrolytes in Unilateral Nephrectomized Rats (UNx).

\begin{tabular}{|c|c|c|c|c|c|}
\hline \multirow{2}{*}{ Parameter } & \multirow{2}{*}{ Time Periods (h) } & & \multirow{2}{*}{ Sham } & \multicolumn{2}{|c|}{ UNx } \\
\hline & & & & Home Cage & Pyramid \\
\hline \multirow{4}{*}{ Sodium (mmol /L ) } & \multirow{2}{*}{24} & Urine & $149.16 \pm 0.78$ & $267.37 \pm 22.57^{\mathrm{a}}$ & $256.84 \pm 15.11^{\mathrm{a}}$ \\
\hline & & Serum & $357.90 \pm 19.85$ & $208.73 \pm 1.14^{\mathrm{a}}$ & $209.37 \pm 1.51^{\mathrm{a}}$ \\
\hline & \multirow{2}{*}{48} & Urine & $148.31 \pm 2.66$ & $253.68 \pm 11.43^{\mathrm{a}}$ & $249.47 \pm 5.97^{a}$ \\
\hline & & Serum & $362.96 \pm 21.49$ & $218.03 \pm 32.25^{\mathrm{a}}$ & $249.47 \pm 5.97^{\mathrm{a}}$ \\
\hline \multirow{4}{*}{ Potassium (mmol /L ) } & \multirow{2}{*}{24} & Urine & $13.11 \pm 2.19$ & $9.83 \pm 1.28^{\mathrm{a}}$ & $11.42 \pm 0.51^{\mathrm{a}}$ \\
\hline & & Serum & $8.95 \pm 2.59$ & $13.94 \pm 1.06^{\mathrm{a}}$ & $10.07 \pm 0.54^{\mathrm{a}}$ \\
\hline & \multirow{2}{*}{48} & Urine & $13.06 \pm 0.40$ & $9.57 \pm 0.62^{\mathrm{a}}$ & $10.64 \pm 1.84^{\mathrm{ab}}$ \\
\hline & & Serum & $8.91 \pm 0.10$ & $11.00 \pm 0.35^{\mathrm{a}}$ & $9.33 \pm 2.04^{\mathrm{a}}$ \\
\hline \multirow{4}{*}{ Calcium (mmol /L) } & \multirow{2}{*}{24} & Urine & $3.35 \pm 0.10$ & $7.17 \pm 0.81^{\mathrm{a}}$ & $6.22 \pm 1.32^{\mathrm{ab}}$ \\
\hline & & Serum & $6.14 \pm 0.94$ & $3.02 \pm 0.32^{\mathrm{a}}$ & $3.93 \pm 0.63^{\mathrm{ab}}$ \\
\hline & \multirow{2}{*}{48} & Urine & $3.23 \pm 0.23$ & $6.48 \pm 1.48^{\mathrm{a}}$ & $5.39 \pm 1.06^{\mathrm{ab}}$ \\
\hline & & Serum & $6.29 \pm 1.62$ & $4.37 \pm 0.28^{\mathrm{a}}$ & $5.50 \pm 0.34^{\mathrm{ab}}$ \\
\hline
\end{tabular}

Note: Values are means \pm SEM $(n=7$ per group). a: Significant at $(\mathrm{P}<0.05)$ as compared to the corresponding sham group. b: Significant at $(\mathrm{P}<0.05)$ as compared to the corresponding home cage group. 
Effect of Egyptian Pyramid Housing on Serum Creatinine and Creatinine Clearance Levels in Unilateral Nephrectomized Rats (UNx)

Data illustrated in Table 3 recorded significant reduction $(\mathrm{P}<0.05)$ in the creatinine level of UNx rats either housed inside their home cages or inside the Egyptian pyramid model for 24 and $48 \mathrm{~h}$ as compared to the corresponding sham groups. However, serum creatinine level significantly increased $(\mathrm{P}<0.05)$ in $\mathrm{UNx}$ rats either housed inside their home cages or inside the Egyptian pyramid model for 24 and $48 \mathrm{~h}$ as compared to the corresponding sham groups (Table 3). The creatinine clearance significantly decreased $(\mathrm{P}<0.05)$ in $\mathrm{UNx}$ rats housed in their home cages and inside the Egyptian pyramid model following $24 \mathrm{~h}$ of nephrectomy. On the other hand, creatinine clearance increased significantly $(\mathrm{P}<0.05)$ only after housing $\mathrm{UNx}$ rats inside the Egyptian pyramid model following $48 \mathrm{~h}$ (Table 3).

Table 3: Effect of Egyptian pyramid housing on serum creatinine and creatinine clearance levels in unilateral nephrectomized rats (UNx).

\begin{tabular}{|c|c|c|c|c|c|}
\hline \multirow{2}{*}{ Parameter } & \multirow{2}{*}{ Time Periods (h) } & & \multirow{2}{*}{ Sham } & \multicolumn{2}{|c|}{ UNx } \\
\hline & & & & Home cage & Pyramid \\
\hline \multirow{4}{*}{ Creatinine (mg /dL ) } & \multirow{2}{*}{24} & Urine & $145.00 \pm 12.09$ & $94.62 \pm 13.14 \mathrm{a}$ & $119.84 \pm 4.19 \mathrm{ab}$ \\
\hline & & Serum & $2.35 \pm 0.34$ & $5.22 \pm 0.46 a$ & $4.32 \pm 0.27 \mathrm{ab}$ \\
\hline & \multirow{2}{*}{48} & Urine & $145.03 \pm 1.84$ & $101.25 \pm 10.35 \mathrm{a}$ & $148.75 \pm 11.08 \mathrm{ab}$ \\
\hline & & Serum & $2.06 \pm 0.16$ & $4.69 \pm 0.14 \mathrm{a}$ & $3.01 \pm 0.38 \mathrm{ab}$ \\
\hline \multirow{4}{*}{$\begin{array}{l}\text { Creatinine Clearance } \\
\qquad(\mathrm{ml} / \mathrm{min})\end{array}$} & \multirow{2}{*}{24} & Urine & $0.37 \pm 0.04$ & $0.13 \pm 0.02 \mathrm{a}$ & $0.32 \pm 0.03 b$ \\
\hline & & Serum & $0.16 \pm 0.01$ & $0.13 \pm 0.01$ & $0.29 \pm 0.03 \mathrm{ab}$ \\
\hline & \multirow{2}{*}{48} & Urine & $2.35 \pm 0.34$ & $5.22 \pm 0.46 a$ & $4.32 \pm 0.27 \mathrm{ab}$ \\
\hline & & Serum & $145.03 \pm 1.84$ & $101.25 \pm 10.35 a$ & $148.75 \pm 11.08 \mathrm{ab}$ \\
\hline
\end{tabular}

Note: Values are means \pm SEM $(n=7$ per group). a: Significant at $(\mathrm{P}<0.05)$ as compared to the corresponding sham group. b: Significant at $(\mathrm{P}<0.05)$ as compared to the corresponding home cage group.

Effect of Egyptian Pyramid Housing on Some Urine and Serum Kidney Function Parameters in Unilateral Nephrectomized Rats (UNx)

Figures 2 \& 3 demonstrated significant increase $(\mathrm{P}<0.05)$ in proteinuria with concomitant significant decrease $(\mathrm{P}<0.05)$ in total serum protein level in home cage UNx group as compared to sham group after 24 and $48 \mathrm{~h}$ following nephrectomy. The obtained data also showed significant decrease $(\mathrm{P}<0.05)$ in the levels of urine urea and uric acid in home cage UNx rats as compared to sham group (Figures 4-7). On the other hand, their levels increased significantly in the serum $(\mathrm{P}<0.05)$ of home cage UNx rats after 24 and $48 \mathrm{~h}$ following nephrectomy. However, housing of rats inside the Egyptian pyramids for 24 and $48 \mathrm{~h}$ significantly $(\mathrm{P}<0.05)$ ameliorate these effects and restore their levels towards the control values (Figures 4-7).

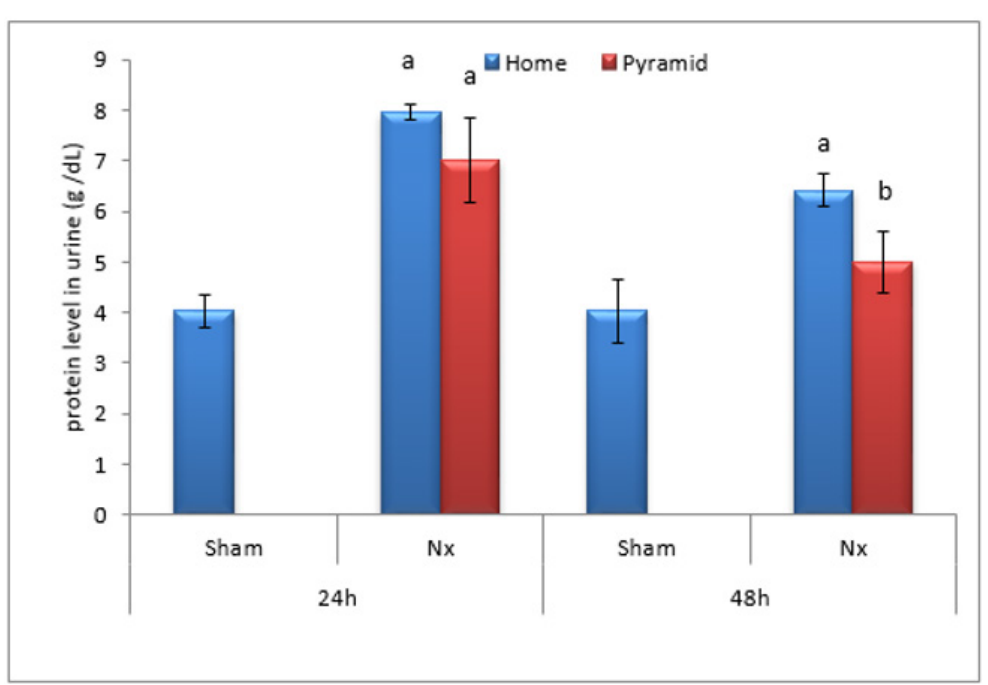

Figure 2: Effect of Egyptian pyramid housing on urine protein level (g/dl) and in Unilateral Nephrectomized Rats (UNx). Values are means \pm SEM ( $n=7$ per group). a: Significant at $(\mathrm{P}<0.05)$ as compared to the corresponding sham group. b: Significant at $(\mathrm{P}<0.05)$ as compared to the corresponding home cage group. 


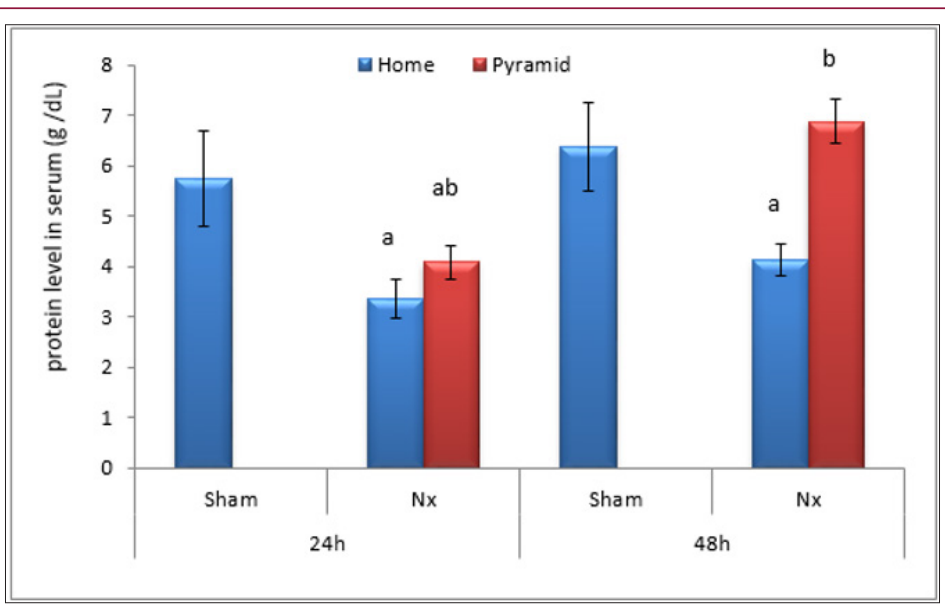

Figure 3: Effect of Egyptian pyramid housing on serum protein level (g/dl) and in Unilateral Nephrectomized Rats (UNx). Values are means \pm SEM ( $n=7$ per group). a: Significant at $(\mathrm{P}<0.05)$ as compared to the corresponding sham group. $b$ : Significant at $(\mathrm{P}<0.05)$ as compared to the corresponding home cage group.

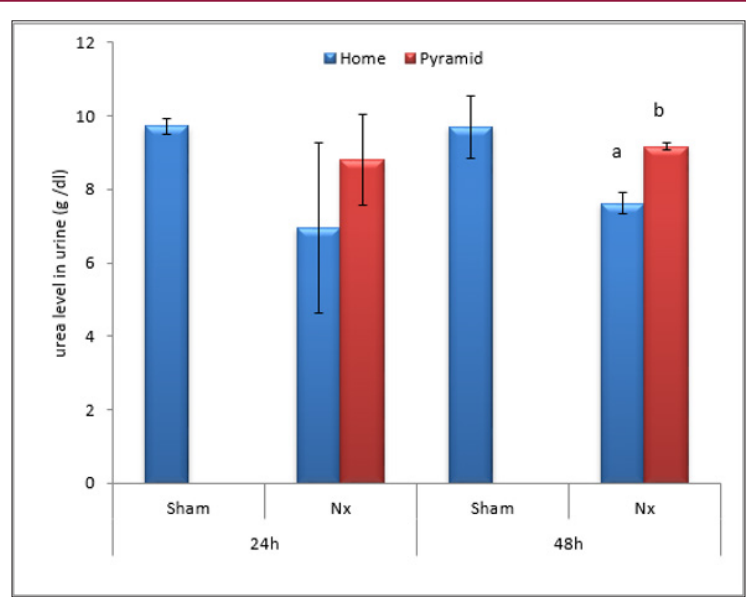

Figure 4: Effect of Egyptian pyramid housing on urea level in urine (g/dl) and in Unilateral Nephrectomized Rats (UNx). Values are means \pm SEM ( $n=7$ per group). a: Significant at $(\mathrm{P}<0.05)$ as compared to the corresponding sham group. b: Significant at $(\mathrm{P}<0.05)$ as compared to the corresponding home cage group.

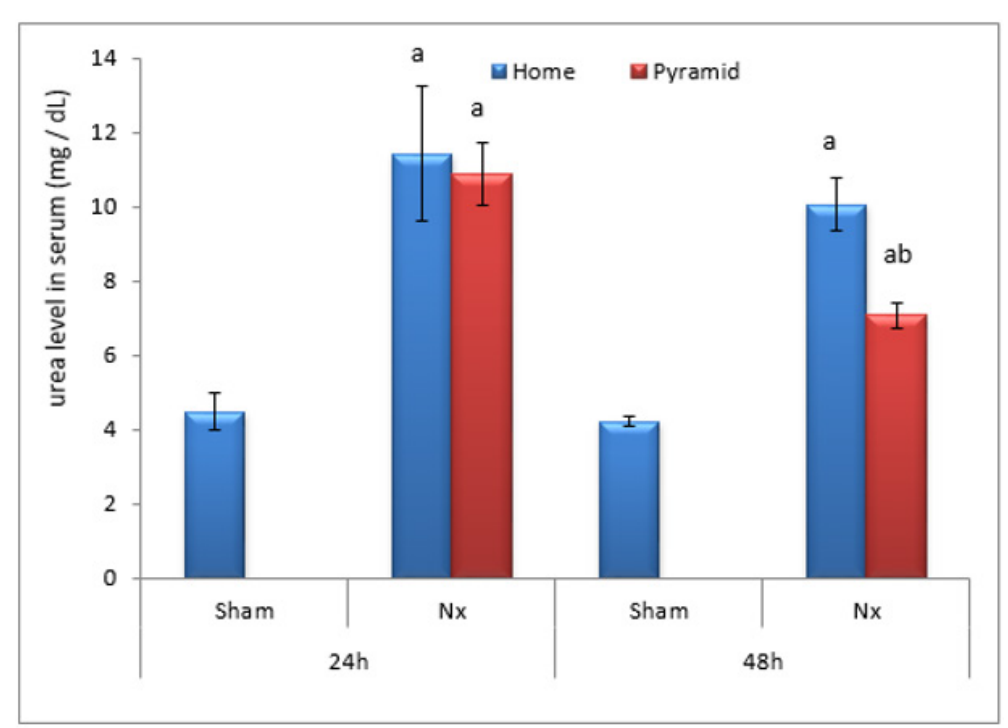

Figure 5: Effect of Egyptian pyramid housing on serum urea level (g/dl) and in Unilateral Nephrectomized Rats (UNx). Values are means \pm SEM ( $n=7$ per group). a: Significant at $(\mathrm{P}<0.05)$ as compared to the corresponding sham group. b: Significant at $(\mathrm{P}<0.05)$ as compared to the corresponding home cage group. 


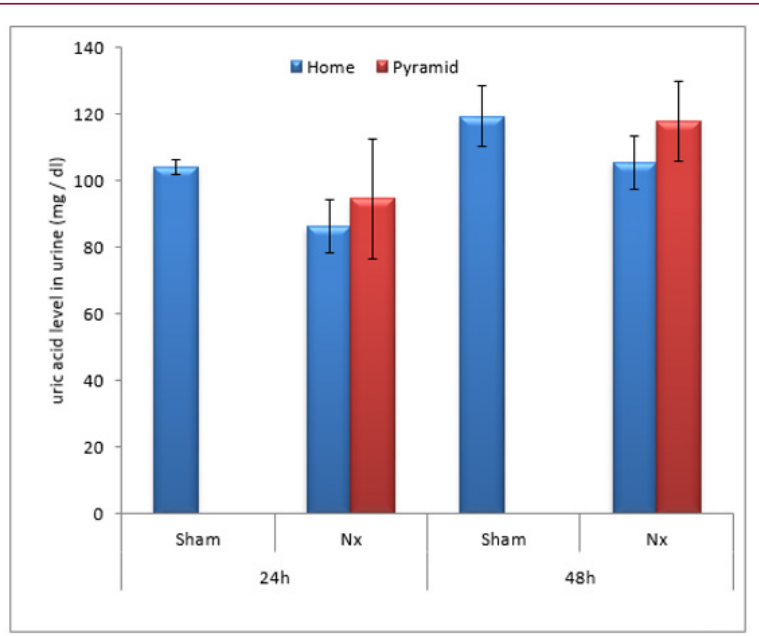

Figure 6: Effect of Egyptian pyramid housing on urine uric acid level (mg/dl) in Unilateral Nephrectomized Rats (UNx). Values are means \pm SEM ( $n=7$ per group). a: Significant at $(\mathrm{P}<0.05)$ as compared to the corresponding sham group. b: Significant at $(\mathrm{P}<0.05)$ as compared to the corresponding home cage group.

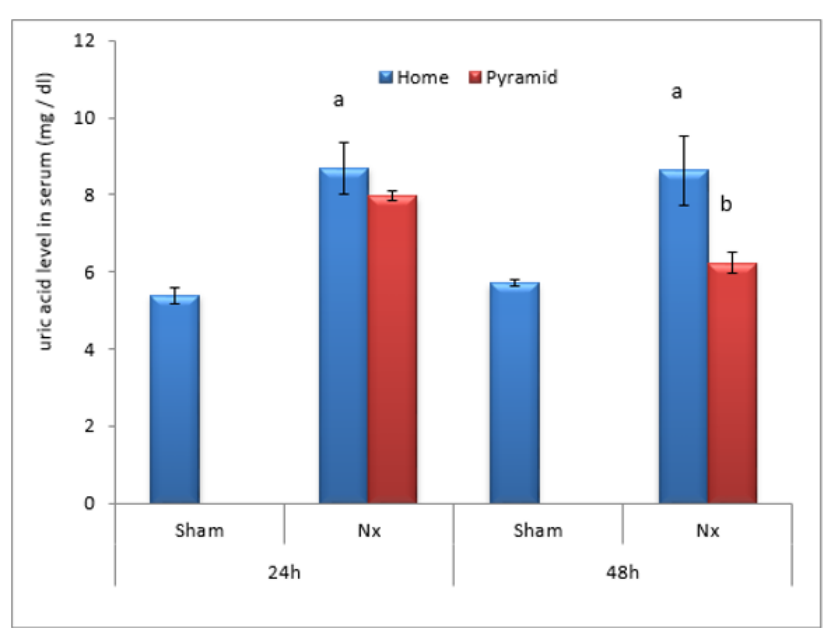

Figure 7: Effect of Egyptian pyramid housing on serum uric acid level (mg/dl) and in Unilateral Nephrectomized Rats (UNx). Values are means \pm SEM ( $n=7$ per group). a: Significant at $(\mathrm{P}<0.05)$ as compared to the corresponding sham group. $b$ : Significant at $(\mathrm{P}<0.05)$ as compared to the corresponding home cage group.

Effect of Egyptian Pyramid Housing on Reinin, Angiotensin and Aldosterone in Unilateral Nephrectomized Rats (UNx)

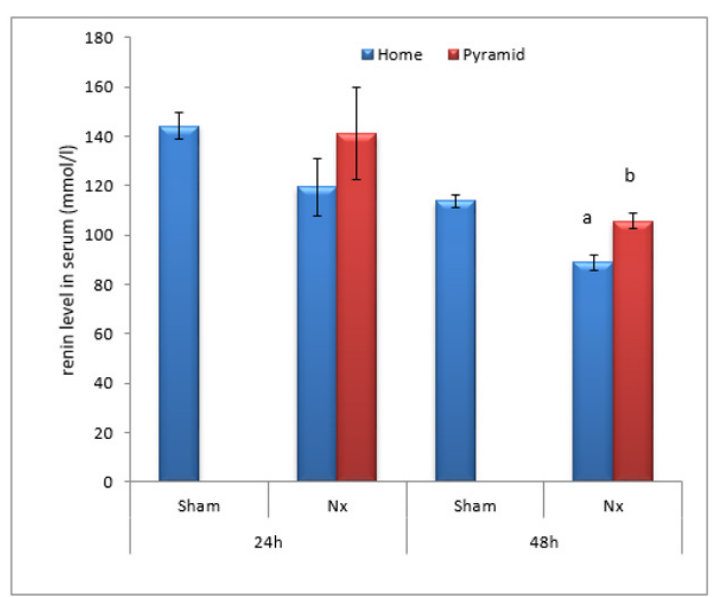

Figure 8: Effect of Egyptian pyramid housing on renin level (mmol/l) and in Unilateral Nephrectomized Rats (UNx). Values are means \pm SEM ( $n=7$ per group). a: Significant at $(\mathrm{P}<0.05)$ as compared to the corresponding sham group. b: Significant at $(\mathrm{P}<0.05)$ as compared to the corresponding home cage group. 
Data illustrated in Figures 8-10 showed significant decrease $(\mathrm{P}<0.05)$ in the levels of serum reinin, angiotensin and aldosterone following unilateral nephrectomy in rats as compared to sham group. Levels of the studied hormones significantly increased after housing UNx rats inside the Egyptian pyramid for 24 and $48 \mathrm{~h}$.

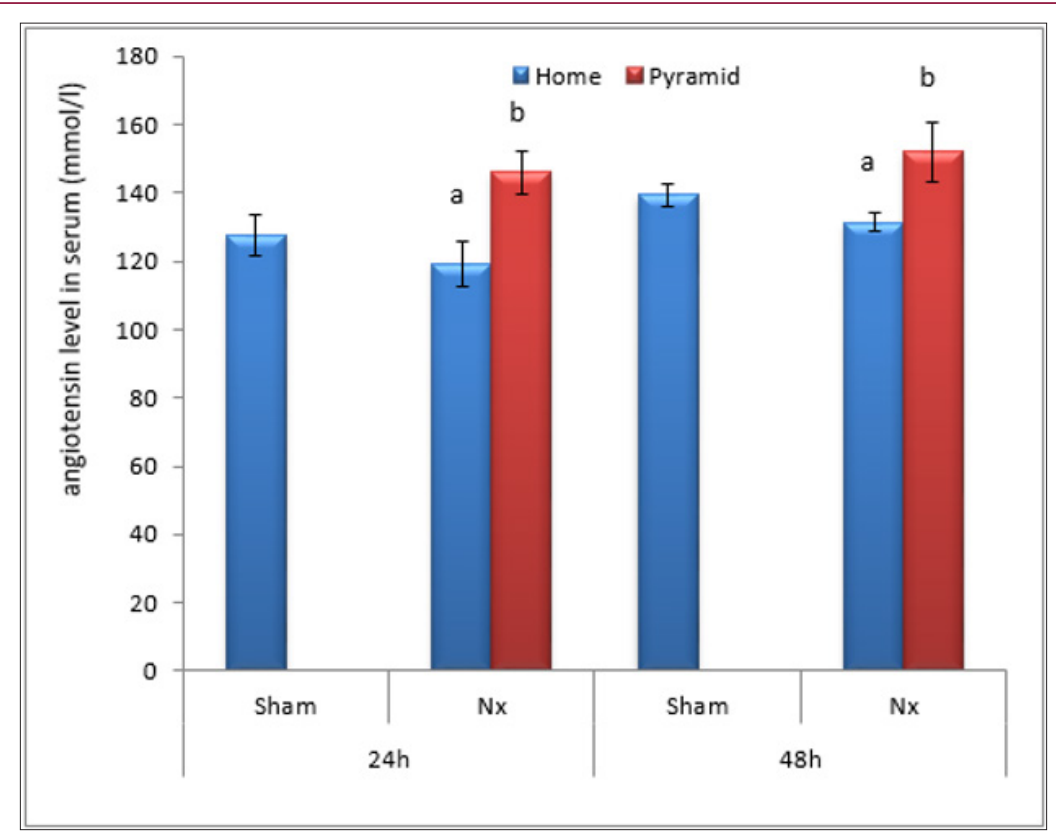

Figure 9: Effect of Egyptian pyramid housing on angiotensin level (mmol/l) and in Unilateral Nephrectomized Rats (UNx). Values are means \pm SEM ( $n=7$ per group). a: Significant at $(\mathrm{P}<0.05)$ as compared to the corresponding sham group. b: Significant at $(\mathrm{P}<0.05)$ as compared to the corresponding home cage group.

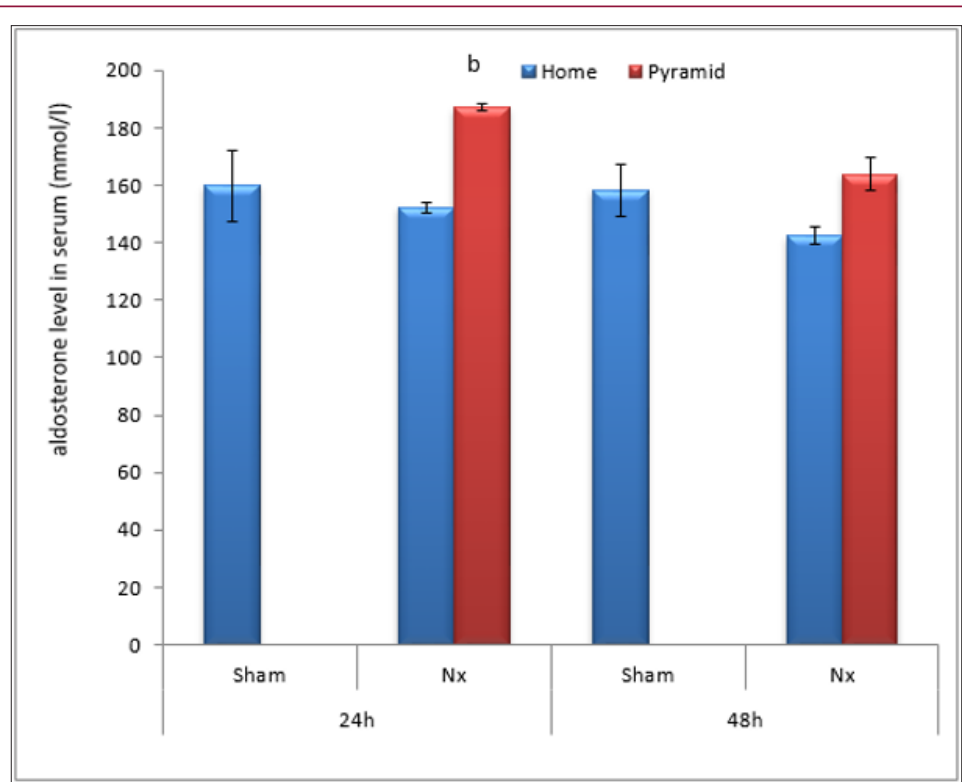

Figure 10: Effect of Egyptian pyramid housing on aldosterone level (mmol/l) and in Unilateral Nephrectomized Rats (UNx). Values are means \pm SEM ( $n=7$ per group). a: Significant at $(P<0.05)$ as compared to the corresponding sham group. b: Significant at $(\mathrm{P}<0.05)$ as compared to the corresponding home cage group.

\section{Histological Findings}

Figure 11 illustrate the histological alterations in kidney of UNx rats following housing inside the Egyptian pyramid model. Figure $11 \mathrm{~A} \& 11 \mathrm{~B}$ represent microscopic examination of kidney in sham groups showing normal renal tubules and renal glomeruli. Dilated glomeruli with focal area of vacuolated renal tubules (arrows) were observed in UNx rats housed inside their cages for 24 and $48 \mathrm{~h}$ (Figure 11C \& 11D). Housing UNx rats for 24 and $48 \mathrm{~h}$ inside the pyramid model demonstrated healthy renal tissue (Figure 11E \& $11 \mathrm{~F})$. 


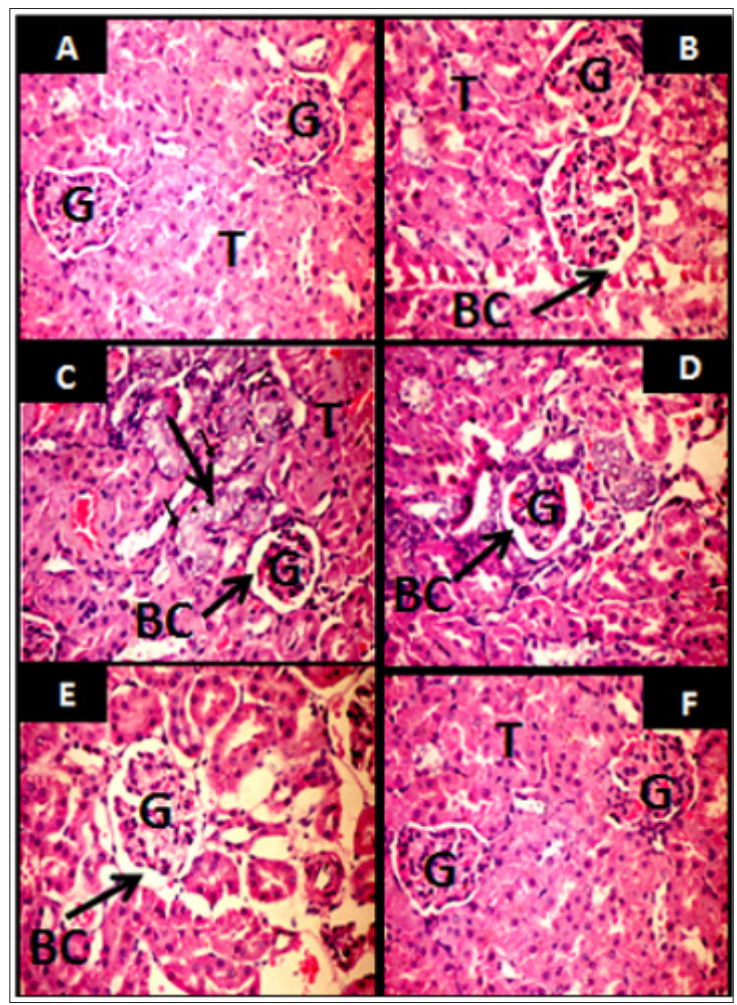

Figure 11: Light micrographs of representative kidney sections (Haematoxylin and Eosin stain, $x$ 400) from sham rats (A,B), Unilateral Nephrectomized (UNx) rats housed inside their home cages for 24 and $48 \mathrm{~h}$ respectively (C\&D) and UNx rats housed under the pyramid model environment for 24 and $48 \mathrm{~h}$ respectively (E\&F). G: glomerulus, BC: Bowman's capsule, T: tubules.

\section{Discussion}

The pyramid shape is being seen as a supernatural source of energy of the universe. The energy power inside the pyramids is a way to recover the Electro-Magnetic Fields (EMF) that have been essential for the communication of living cells [21]. Now the pyramids are being used very efficiently for balancing the centres of energy in human body, medical healing and anti-stress effects $[22,23]$. To our knowledge the effectiveness of the Egyptian pyramid model housing in preventing the renal failure following surgical resection of renal carcinoma not studied till now. Thereby, the present study postulated that housing of nephrectomized rats in the early stages ( 24 and $48 \mathrm{~h}$ ) inside a model of the Egyptian pyramid may be preventing renal failure that concomitant with the Unilateral Nephrectomy (UNx).

One of the best recognized mechanisms of renal failure following nephrectomy is hyperfiltration in the remaining nephrons, which is then thought to induce focal and segmental glomerulosclerosis, further damaging the remaining nephrons [24,25]. Thereby, the remaining kidney increases in size in response to hyperfiltration and begins to compensate for its missing partner [26,27]. The loss of renal mass or UNx is associated with functional and morphological adaptations in the remaining tissue. The most prominent response after UNx is an increase in size and weight of the remaining kidney. In consonance with the previous suggestion, the present study confirmed the finding of Gava et al. [28] and Mjøen et al. [29], who recorded significant increase in the weight of right kidney following UNx in rats. Moreover, Abdellatif et al. [30] reported that UNx may be associated with enlargement and hypertrophy of the remaining kidney.

However, the compensatory renal growth occurred in UNx rats either housed in their home cages or inside the pyramids. To determine if the compensatory renal growth in UNx rats accompanied with renal failure or not, the present study continued to investigate kidney function. The serum levels of urea and creatinine are often considered as reliable markers for measurement of renal function [31]. In agreement with the report of Baracho et al. [32] and Bai et al. [33] the present study recorded marked decrease in urea, uric acid and creatinine levels in the urine of UNx rats housed inside their home cages concomitant with marked increase in their levels in the serum. The impairment in the levels of urea and creatinine in the urine and serum following nephrectomy may indicates destructive in the ability of the kidneys to filter these waste products from the blood and excrete them in urine $[34,28]$. Housing UNx rats in the pyramid model for 24 and $48 \mathrm{~h}$ induced enhancement in the kidney function as indicated by improvement in the levels of studied parameters.

Proteinuria is thought to reflect glomerular hypertension and hyperfiltration in the single kidney and to anticipate renal functional decline [35]. In consonance with the finding of Ibrahim et al. [36] and Zhong et al. [27], the present investigation recorded significant proteinuria in UNx rats housed in their home cages for 24 and $48 \mathrm{~h}$. Proteinuria is considered to be a marker of dysfunction of the glomerular filtration barrier [37]. The obtained results demonstrated that housing UNx rats under the pyramid model 
environment can significantly reduce proteinuria in the early stages. Renal function is most widely assessed by Glomerular Filtration Rate (GFR), either measured or estimated. Direct measurements of GFR are uncommonly performed on partial nephrectomy patients. Therefore, most partial nephrectomy renal function studies rely on estimates of glomerular filtration based on serum creatinine [38]. In conjunction with the report of Zorn et al. [39], Chapman et al. [40]; Nutter et al. [41] and Saito et al. [42], UNx is associated with an acute and significant drop in the GFR which may be due to the immediate loss of renal mass. The data recorded in the present investigation showed more increase in the GFR of the UNx rats housed inside the pyramid model for 24 and $48 \mathrm{~h}$ which may suggest predominantly hemodynamic response and more efficient hyperfiltration [35,26]. In agreement with the reports of Wesson [43] and Bohlouli et al. [44], the increment in the GFR could be due to compensatory changes in the remaining kidney. However, the increase in the GFR following housing UNx rats under the pyramid environment may be due to an increase in kidney weight and an increase in the GFR per gram of kidney [45]. In addition, the GFR of the remaining kidney need to be increased to maintain fluid and electrolyte balance, through adjustments in vasomotor control of the microvasculature [46].

The concentration of $\mathrm{Na}+$ and $\mathrm{K}+$ electrolytes in the extracellular fluid is maintained by the kidneys [47]. The present study supported the reports of Gava et al. [28]; Calunga et al. [48] who recorded significant rise in the rate of sodium excretion in UNx rat's concomitant with its increase in the serum. This increase may be attributed to a decline in the fractional sodium reabsorption in proximal tubules [49]. The high rate of sodium, potassium and clacium excretion in urine may be due to the increased filtration burden on the remnant glomeruli which could leads to increased excretion of ions from and the decreased accumulation of ions in the plasma [50]. Housing of Nx rats inside the Egyptian pyramids did not affect levels of electrolytes in urine and serum which may suggest that housing inside the pyramide model ameliorate kidney function through certain mechanism other that homeostasis of electrolytes.

The Renin-Angiotensin System (RAS) is a major regulator of sodium and water homeostasis, vascular resistance, and ultimately arterial blood pressure [51]. The classical RAS consists of a circulating endocrine system in which the principal effectors' hormone is angiotensin II. Angiotensin II is a key biologic peptide in the Renin-Angiotensin System (RAS) that regulates blood pressure and renal hemodynamics [52]. The present study supported the finding of Dilauro et al. [53], who reported reduction in plasma Ang II following nephrectomy in rats which may be due to secondary suppression of systemic RAS. Normally, an increase in fluid delivery to the macula densa, will initiate afferent arteriolar vasoconstriction due to activation of the Tubuloglomerular Feedback (TGF) system [54]. The TGF feedback is a negative-feedback system operating within the juxtaglomerular apparatus that can regulate GFR by changing arteriolar resistance and hence blood flow and pressure into the glomerular capillaries [55]. Housing $\mathrm{UNx}$ rats inside pyramid model restore normal level of RAS which may indicate that the pyramid provide good environment for adaptations after nephrectomy without negative consequences for renal function, despite the fact that glomerular hypertension and hyperfiltration can cause glomerular damage. Moreover, the energy field developed within the pyramid may increase the GFR by increase in the renal blood flow which stimulate renin production and enhance RAS system that increasing sodium reuptake.

\section{Conclusion}

The present study showed that housing nephrectomized rats inside model of the Egyptian pyramid may be a potential new strategy prevents CKD following renal tumor resection. Also, the current study suggested that pyramid environment plays an important role in ameliorating the serious effects of nephrectomy by enhancing kidney function. However, further studies are necessary to elucidate the mechanism by which pyramid environment reversed the actions of nephrectomy in rats.

\section{References}

1. Robson CJ, Churchill BM, Anderson W (1969) The results of radical nephrectomy for renal cell carcinoma. J Urol 101(3): 297-301.

2. Levey AS, Coresh J (2012) Chronic kidney disease. Lancet 379(9811): 165-180.

3. Ismail B, deKemp RA, Hadizad T, Mackasey K, Beanlands RS, et al. (2016) Decreased renal AT1 receptor binding in rats after subtotal nephrectomy: PET study with [(18)F]FPyKYNE-losartan. EJNMMI Res 6(1): 55.

4. Aparicio Trejo OE, Tapia E, Molina Jijón E, Medina Campos ON, Macías Ruvalcaba NA, et al. (2016) Curcumin prevents mitochondrial dynamics disturbances in early 5/6 nephrectomy: Relation to oxidative stress and mitochondrial bioenergetics. Biofactors 43(2): 293-310.

5. Lane PH (1999) Long-term furosemide treatment in the normal rat: dissociation of glomerular hypertrophy and glomerulosclerosis. Am J Kidney Dis 33(6): 1058-1063.

6. Lin SL, Chen YM, Chiang WC, Tsai TJ, Chen WY (2004) Pentoxifylline: A potential therapy for chronic kidney disease. Nephrology (Carlton) 9(4): 198-204.

7. Bhat S, Rao G, Murthy KD, Bhat PG (2010) Alterations in stress parameters in rats housed in a pyramid model - Seasonal variations. J Pha Bio Sci Int 1(2).

8. Schul B, Pettit E (1975) The secret power of pyramids. In Schul B, Pettit E (Eds.) ( $1^{\text {st }}$ edn). Random House Publishing Group, New York, USA.

9. Cope FW (1980) Magnetic currents in flowing water: Implications for magnetic water and for the immune processes. J Physiol Chem Phy 12: 21-29.

10. Kronenberg K (1985) Experimental evidence for effects of magnetic fields on moving water. IEEE Transactions on Magnetics 21(5).

11. Razumov AN, Karpukhin IV, Kiiatkin VA, Esilevskillu M, Ufimtseva AG (2001) The effect of ultra-high frequency electromagnetic fields on the intrarenal blood flow and kidney morphology in pyelonephritis (experimental study). Vopr Kurortol Fizioter Lech Fiz Kult 2: 3-8.

12. Fahmy SR, Gaafar K, Sayed DA, Nageeb H (2016) Egyptian pyramid model housing enhancing the compensatory renal growth in nephrectomized rats. J Complement Med Alt Healthcare 1(1): 1-8.

13. Bhat S, Rao G, Murthy KD, Bhat PG (2006) Housing in pyramid counteracts neuroendocrine and oxidative stress caused by chronic restraint in rats. Evid Based Complement Alternat Med 4(1): 35-42.

14. Trinder PA (1951) Rapid method for the determination of sodium in serum 76(907): 596. 
15. Sunderman, Sunderman FW (1958) Determination of potassium. Am Clin Pathol 29: 95.

16. Gindler M, King JD (1972) Chemical method for determination of calcium in serum. Am J Clin Pathol 58: 376.

17. Fawcett JK, Scott JE (1960) A rapid and precise method for the determination of urea. J Clin Pathol 13(2): 156.

18. Gornal AG, BardaC JW, David MM (1949) Determination of serum proteins by means of the biuret reagent. J Biol Chem 177: 751-766.

19. Barham D, Trinder P (1972) An improved colour reagent for the determination of blood glucose by the oxidase system. Analyst 97: 142145.

20. Schirmeister J (1964) Determination of creatinine in serum. Dtsch Med Wschr 89: 1940.

21. El Abiad NM, Lotfi SA, El Hadary AMA, Nagi GA (2010) A study on radiation energy of Pyramidal shape 1- Effect of housing within a Pyramid model on cancer growth and some blood parameters of mice. Rad Res Appl Sci J 3(4A): 1211-1224.

22. Bhat S, Rao G, Murthy KD, Bhat PG (2003) Effect of housing rats within a pyramid on stress parameters. Indian J Exp Biol 41(11): 1289-1293.

23. Kamath S, Rad SG, Murthy KD, Bairy KL, Bhat S (2006) Enhanced wound concentration and epithelization period in steroid treated rats: role of pyramid environment. Indian J Experimental Biology 44(11): 902-904.

24. Elsherbiny HE, Alexander MP, Kremers WK, Park WD, Poggio ED, et al. (2014) Nephron hypertrophy and glomerulosclerosis and their association with kidney function and risk factors among living kidney donors. Clin J Am Soc Nephrol 9(11): 1892-1902.

25. Meyrier A (2015) Nephrosclerosis: Update on a centenarian. Nephro Dial Transplant 30(11): 1833-1841.

26. Cutajar M, Hilton R, Olsburgh J, Marks SD, Thomas DL, et al. (2015) Renal blood flow using arterial spin labelling MRI and calculated filtration fraction in healthy adult kidney donor's pre-nephrectomy and postnephrectomy. Eur Radiol 25: 2390-2396.

27. Zhong F, Mallipattu SK, Estrada C, Menon M, Salem F, et al. (2016) Reduced krüppel-like factor 2 aggravates glomerular endothelial cell injury and kidney disease in mice with unilateral nephrectomy. Am J Pathol 186(8): 2021-2031.

28. Gava AL, Freitas FP S, Balarini CM, Vasque EC, Meyrelles SS (2012) Effects of 5/6 nephrectomy on renal function and blood pressure in mice. Int J Physiol Pathophysiol Pharmacol 4(3): 167-173.

29. Mjoen G, Hallan S, Hartmann A, Foss A, Midtvedt K, et al. (2014) Longterm risks for kidney donors. Kidney Int 86(1): 162-167.

30. Abdellatif AM, Alsayed SA, Hassan YM (2013) Effects of Uninephrectomy on morphological and histological measurements of the remnant kidney in a goat (Capra hircus) Model. J Phys Pharm Adv 3(3): 94-102.

31. Vanholder R, Baurmeister U, Brunet P, Cohen G, Glorieux G, et al. (2008) A bench to beside view of uremic toxins. J Am Soc Nephrol 19(5): 863870 .

32. Baracho NC, Kangussu LM, Prestes TR, Silveira KD, Pereira RM, et al (2016) Characterization of an experimental model of progressive renal disease in rats. Acta Cir Bras 31(11): 744-752.

33. Bai J, Hao J, Zhang X, Cui H, Han J, et al. (2016) Netrin-1 attenuates the progression of renal dysfunction by blocking endothelial-tomesenchymal transition in the 5/6 nephrectomy rat model. BMC Nephrol 17(1): 47.

34. Orsić V, Mihalj M, Mogus M, Mihalj H, Jakić M, et al. (2011) Impaired kidney function in rats six months after unilateral nephrectomy - an old story, a new perspective. Med Glas Zenica 8: 185-191.
35. Mueller TF, Luyckx VA (2012) The natural history of residual renal function in transplant donors. Am J Soc Nephrol 23: 1462-1466.

36. Ibrahim HN, Foley R, Tan L, Rogers T, Bailey RF, et al. (2009) Long-term consequences of kidney donation. N Engl J Med 360: 459-469.

37. Agrawal V, Marinescu V, Agarwal M, McCullough PA (2009) Cardiovascular implications of proteinuria: An indicator of chronic kidney disease. Nat Rev Cardiol 6(4): 301-311.

38. Breau RH, Clark AT, Morash C, Fergusson D, Cagiannos I (2011) Associations between radiographic characteristics and change in renal function following partial nephrectomy using 24-hour creatinine clearance. Can Urol Assoc J 5(1): 45-48.

39.Zorn KC, Gong EM, Orvieto MA, Gofrit ON, Mikhail AA, et al. (2007) Comparison of laparoscopic radical and partial nephrectomy: Effects on long-term serum creatinine. Urology 69: 1035-1040.

40. Chapman D, Moore R, Klarenbach S, Braam B (2010) Residual renal function after partial or radical nephrectomy for renal cell carcinoma. J Can Uro 4: 337-334.

41. Nutter FH, Haylor JL, Khwaja A (2015) Inhibiting ERK activation with CI-1040 leads to compensatory upregulation of alternate MAPKs and plasminogen activator inhibitor-1 following subtotal nephrectomy with no impact on kidney fibrosis. PLoS One 10(9): 0137321.

42. Saito T, Uchida K, Ishida H, Tanabe K, Nitta K (2015) Changes in glomerular filtration rate after donation in living kidney donors: A single-center cohort study. Int Urol Nephrol 47(2): 397-403.

43. Wesson LG (1989) Compensatory growth and other growth responses of the kidney. Nephron 51: 149-184.

44. Bohlouli A, Tarzamni MK, Zomorodi A, Abdollahifard S, Hashemi B, et al. (2010) Remnant kidney function and size in living unrelated kidney donors after nephrectomy. Saudi J Kidney Dis Transpl 21(2): 246-250.

45. Provoost AP, Molenaar JC (1980) Changes in the glomerular filtration rate after unilateral nephrectomy in rats. Pflugers Arch 385(2): 161-165.

46. Carmines PK, Fleming JT (1990) Control of the renal microvasculature by vasoactive peptides. FASEB J 4: 3300-3309.

47.Pall K, Kumar MV (2011) Exploring solid lipid nanoparticles for intranasal administration of streptomycin. Int J Pharma 1: 110-117.

48. Calunga JL, Zamora ZB, Borrego A, Río Sd, Barber E, et al. (2005) Ozone therapy on rats submitted to subtotal nephrectomy: Role of antioxidant system. Mediators Inflamm 2005(4): 221-227.

49. Diezi J, Michoud P, Aceves J, Giebisch G (1973) Micropuncture study of electrolyte transport across papillary collecting duct of the rat. Am J Physiol 224: 623-634

50. Kwon TH, Frøkiaer J, Fernández Llama P, Maunsbach AB, Knepper MA, et al. (1999) Altered expression of Na transporters NHE-3, NaPi-II, Na-KATPase, BSC-1, and TSC in CRF rat kidneys. Am J Physiol 277: F257-270.

51. Luo H, Wang X, Chen C, Wang J, Zou X, et al. (2015) Oxidative stress causes imbalance of Renal Renin Angiotensin System (RAS) components and hypertension in obese Zucker rats. J Am Heart Assoc 4(2): e001559.

52. Miyajima A, Yazawa S, Kosaka T, Tanaka N, Shirotake S, et al. (2015) Prognostic impact of renin-angiotensin system blockade on renal cell carcinoma after surgery. Ann Surg Oncol 22(11): 3751-3759.

53. Dilauro M, Zimpelmann J, Robertson SJ, Genest D, Burns KD (2010) Effect of ACE2 and angiotensin-(1-7) in a mouse model of early chronic kidney disease. Am J Physiol Renal Physiol 298: F1523-F1532.

54. Komlosi P, Bell PD, Zhang ZR (2009) Tubuloglomerular feedback mechanisms in nephron segments beyond the macula densa. Curr Opin Nephrol Hypertens 18: 57-62.

55. Ito S, Abe K (1996) Tubuloglomerular feedback. Jpn Heart J 37: 153-163. 


\section{ISSN: 2574-1241}

DOI: $10.26717 / B J S T R .2019 .12 .002302$

Sohair R Fahmy. Biomed J Sci \& Tech Res

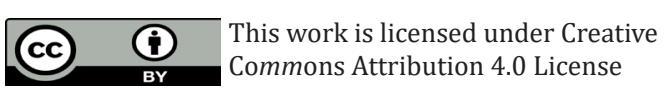

Submission Link: https://biomedres.us/submit-manuscript.php

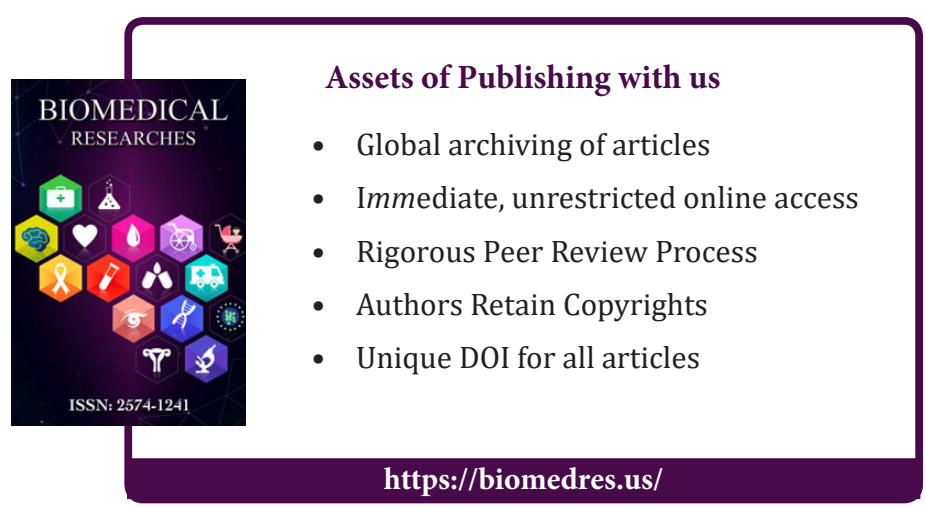

